\title{
VARIABILIDADE GENÉTICA EM TRIGOS BRASILEIROS A PARTIR DE CARACTERES COMPONENTES DA QUALIDADE INDUSTRIAL E PRODUÇÃO DE GRÃOS $\left({ }^{(1)}\right.$
}

\author{
DOUGLAS ANDRÉ MALLMANN SCHMIDT $\left({ }^{2,6}\right)$; FERNANDO IRAJÁ FÉLIX DE CARVALHO $\left({ }^{2 *}\right)$; \\ ANTÔNIO COSTA DE OLIVEIRA $\left({ }^{2}\right)$; JOSÉ ANTÔNIO GONZALEZ DA SILVA $\left({ }^{3}\right)$; IVANDRO BERTAN $\left({ }^{2,5}\right)$; \\ IGOR PIREZ VALÉRIO $\left({ }^{2,6}\right)$; IRINEU HARTWIG $\left({ }^{2,6}\right)$; GUSTAVO DA SILVEIRA $\left({ }^{2,5}\right)$; LUIZ CARLOS GUTKOSKI $\left({ }^{4}\right)$
}

\begin{abstract}
RESUMO
O melhoramento genético para a qualidade industrial do trigo pode representar uma oportunidade de agregar valor de mercado aos produtos agrícolas, sendo o trigo um dos cereais com maior associação entre a qualidade intrínseca e a remuneração ao agricultor. O objetivo do trabalho foi o de determinar a variabilidade genética a partir de caracteres indicativos da qualidade industrial e o rendimento de grãos, e estimar o grau de associação entre estes caracteres em 22 genótipos de trigo. O experimento foi desenvolvido em área experimental pertencente à Universidade Federal de Pelotas, Capão do Leão (RS). Os resultados indicaram a provável existência de variabilidade genética para os caracteres em estudo, a qual pode auxiliar pesquisadores na escolha de genitores. Cruzamentos artificiais envolvendo os genótipos BRS 208, Rubi e Safira podem ser os mais promissores no intuito de incrementar o ganho genético, tanto para a qualidade industrial quanto para a produtividade de grãos. O rendimento de grãos manifestou correlação negativa com o conteúdo de proteína da farinha revelando que a superioridade genotípica para o rendimento de grãos pode afetar negativamente a proporção protéica. Entretanto, o conteúdo de proteína não evidenciou associação significativa com a força de glúten (indicador da qualidade industrial), revelando que a concentração de proteína da farinha não foi eficiente para predizer a qualidade industrial. Este resultado sugere a possibilidade de obtenção de genótipos superiores para o rendimento de grãos sem comprometer a qualidade industrial.
\end{abstract}

Palavras-chave: Triticum aestivum, L.; escolha de genitores; qualidade de panificação.

( $\left.{ }^{1}\right)$ Recebido para publicação em 14 de junho de 2007 e aceito em 21 de agosto de 2008.

$\left({ }^{2}\right)$ Centro de Genômica e Fitomelhoramento, Departamento de Fitotecnia, Faculdade de Agronomia "Eliseu Maciel" (FAEM), Universidade Federal de Pelotas-UfPel, Campus Universitário, Caixa Postal 354, 96010-900 Pelotas (RS). E-mails: douglas@brasmaxgenetica.com.br; carvalho@ufpel.tche.br; acostol@uga.edu (*) Autor correspondente; bertan.ivandro@gmail.com; igorvalerio@gmail.com; iriwig@gmail.com; gustavo_dasilveira@yahoo.com.br

$\left({ }^{3}\right)$ Universidade Regional do Noroeste do Estado do Rio Grande do Sul, UNIJUI, Caixa Postal 501, $98700-000$ Ijui (RS). E-mail: jags@pesquisador.cnpq.br

(') Universidade de Passo Fundo, UPF, Caixa Postal 611, 98700-000 Passo Fundo (RS). E-mail: gutkoski@upf.tche.br

$\left({ }^{5}\right)$ Bolsista Capes.

$\left({ }^{6}\right)$ Bolsista CNPq. 


\title{
ABSTRACT \\ GENETIC VARIABILITY FOR BREAD MAKING QUALITY AND GRAIN YIELD AMONG BRAZILIAN WHEAT GENOTYPES
}

\begin{abstract}
The breeding for wheat bread making quality represents a great opportunity to incorporate commercial value to agricultural products. Wheat has one of the best relationship between end product quality and farmer earnings. Genetic variability among 22 different genotypes based on bread making quality traits and grain yield and the degree of their association was assessed. This research was performed at Centro Agropecuário da Palma experimental field of Universidade Federal de Pelotas, Capão do Leão (RS), Brazil. The results indicated that it is likely the existence of genetic variability for the assessed traits. BRS 208, Rubi and Safira were the best genotypes for breeding programs aiming at high grain yield and bread making quality. Grain yield showed negative correlation with flour protein content. Thus, grain yield improvement can negatively affect protein content. However, the total protein content did not show a significant correlation with gluten strength, suggesting that the protein in the flour is not efficient for predicting bread making quality. Therefore, selection for grain yield can be performed without affecting bread making quality.
\end{abstract}

Key words: Triticum aestivum, L.; parental selection.

\section{INTRODUÇÃO}

Um programa de melhoramento genético de plantas tem por objetivo principal disponibilizar permanentemente novas constituições genéticas superiores para rendimento e qualidade de grãos, tolerantes a estresses bióticos e abióticos. Para a qualidade industrial, o melhoramento pode representar uma excelente estratégia para agregar valor de mercado aos produtos agrícolas, sendo possível verificar associação entre a qualidade industrial do trigo e a remuneração ao agricultor (Payne, 1987, Mittelmann et al., 2000).

Com ênfase na seleção de genótipos superiores para o caráter qualidade industrial em programas de melhoramento do trigo, pesquisadores têm desenvolvido análises para predizer a qualidade de populações segregantes ou de linhagens, no intuito de descartar precocemente genótipos sem qualidade desejada (PAYNe, 1987). Contudo, estas análises são caracterizadas pela necessidade de mão-de-obra altamente qualificada, de grande quantidade de grãos e pelo elevado custo financeiro. Esses fatores podem tornar inviável o emprego destas análises principalmente nas primeiras gerações, diminuindo a eficiência de seleção em programas de melhoramento (Kuchel et al., 2006).

Para superar as dificuldades verificadas na seleção do caráter qualidade industrial, o emprego de genitores adaptados e com qualidade de panificação (variabilidade genética com menor amplitude para este caráter) pode representar uma excelente alternativa. Esta medida pode permitir a obtenção de populações segregantes com pouca variabilidade genética para qualidade industrial (reduzida segregação para os locos responsáveis pela expressão da qualidade), possibilitando o descarte do emprego de técnicas especificas para avaliação do caráter. Desta forma, o programa de melhoramento pode focar sua atenção principal na seleção de caracteres de interesse agronômico, como os componentes do rendimento de grãos (MANDARINO, 1993; LASzTITY, 2003).

A escolha de genitores com base na variabilidade genética em caracteres fenotípicos pode ser realizada através do conhecimento adquirido no campo pelos melhoristas (feeling). Contudo, quando envolve os caracteres da qualidade industrial, os quais são de difícil mensuração, é necessário o emprego de técnicas específicas para a caracterização dos genitores disponíveis (Lasztity, 2003). Neste sentido, os caracteres força de glúten e conteúdo de proteína têm sido empregados com grande sucesso, como critérios na seleção de genitores com qualidade industrial (Kuchel et al., 2006). Entre os componentes da qualidade do trigo, o glúten (formado pelas proteínas de reserva do grão) é o que expressa maior contribuição na determinação do uso industrial, sendo a força de glúten o caráter empregado para a classificação da qualidade do trigo no Brasil (BRASIL, 1999). Além deste caráter, o conteúdo de proteína tem grande importância, por necessitar de menor quantidade de amostra, ser de aferição mais simples e, estar correlacionado com a força de glúten, permitindo predizer a qualidade industrial a partir do conteúdo protéico (Huifen e Hoseney, 1991; Fufa et al., 2005).

O estudo da variabilidade genética tem sido uma estratégia auxiliar de grande importância, sendo considerada uma ligação entre a conservação e a utilização de recursos genéticos disponíveis (BERTAN, 2005, VIEIRA, et al., 2005). Contudo, é possível verificar na literatura brasileira um volume insuficiente de trabalhos que estimam a variabilidade genética entre 
genótipos de trigo recomendados para a Região Sul do país, com base em caracteres indicativos da qualidade industrial e do rendimento de grãos. Desse modo, trabalhos desta natureza podem viabilizar a inferência conjunta de todos os componentes da qualidade industrial com a produtividade de grãos, auxiliando os melhoristas na escolha de genitores com elevado potencial genético para ambos os caracteres.

O presente trabalho teve como objetivo estimar a variabilidade genética de 22 genótipos de trigo, a partir de caracteres indicativos da qualidade industrial e do rendimento de grãos e, verificar o grau de associação entre eles.

\section{MATERIAL E MÉTODOS}

Neste trabalho, foram testados 22 genótipos de trigo, que representam as principais regiões tritícolas do sul do Brasil. Do total dos genótipos avaliados, nove cultivares e duas linhagens são oriundas da Embrapa Trigo/RS, uma linhagem da Embrapa Clima Temperado/RS, duas cultivares da Fundacep/RS, uma cultivar da Coodetec/PR, quatro cultivares do ICA/PR (Isidoro Carlos Assmann Melhoramento Genético) e três cultivares da OR/RS (OR Melhoramento de Sementes).

O experimento de campo foi instalado no ano agrícola de 2005 no Centro Agropecuário da Palma, na área experimental do Centro de Genômica e Fitomelhoramento $\left(31^{\circ} 52^{\prime}\right.$, latitude Sul; $52^{\circ} 21^{\prime}$, longitude Oeste; altitude $13 \mathrm{~m}$ ) pertencente à Faculdade de Agronomia "Eliseu Maciel" da Universidade Federal de Pelotas, Capão do Leão - RS. Segundo a classificação de Koeppen, o clima é do tipo Cfa, com precipitação pluvial anual média de 1.280 mm (Moreno, 1961) e o solo do tipo Podzólico Vermelho-Amarelo da área de mapeamento Pelotas.

O delineamento experimental utilizado foi o de blocos casualizados com três repetições. A parcela foi considerada a unidade experimental, composta de cinco fileiras, espaçadas de $0,2 \mathrm{~m}$ entre si, com $5 \mathrm{~m}$ de comprimento. A adubação foi realizada de acordo com os resultados da análise de solo. O controle de pragas e moléstias foi efetuado conforme as recomendações da Comissão Sul Brasileira De Pesquisa De Trigo (2005).

O rendimento de grãos (RG) foi estimado nas três linhas centrais da parcela (parcela útil).

Para avaliação da qualidade industrial, as produções de grãos das parcelas das quatro repetições do experimento foram reunidas para obter quantidade suficiente de grãos para determinação das análises físicas, químicas e reológicas. As avaliações foram realizadas no laboratório de Cereais do Centro de Pesquisa em Alimentação (CEPA) da Universidade de Passo Fundo (RS), utilizando métodos oficiais de análise, de acordo com o credenciamento junto ao Ministério da Agricultura, Pecuária e Abastecimento (MAPA).

As análises físicas realizadas incluíram os seguintes caracteres: peso do hectolitro ( $\mathrm{PH})$, expresso em $\mathrm{kg} \mathrm{hL}^{-1}$; massa de mil grãos (MMG) expresso em gramas; extração de farinha (EXT) e farinha de quebra (FQ), determinadas em moinho piloto da marca Chopin, sendo as variáveis expressas em percentagem; os valores de luminosidade $\left(L^{*}\right)$ e intensidade de amarelo $\left(+b^{*}\right)$ de cor da farinha variam entre 0 (preto) e 100 (branco) e o componente "- $b^{* \prime \prime}$ (azul) até " $+b^{* \prime}$ (amarelo), respectivamente, determinadas em espectrofotômetro de refletância difusa (Hunter Lab), modelo ColorQuest II, com sensor ótico geométrico de esfera.

As análises químicas realizadas foram: número de queda (NQ), determinado através do uso do aparelho Falling Number e expresso em segundos; teor de proteína da farinha (CP) e teor de cinzas (CC), ambos determinados em espectrômetro de infravermelho proximal (NIR), marca Perstorp Analytical e utilizada a curva de calibração fartam construída pelo laboratório de Físico-Química do Cepa, sendo, respectivamente, expressos em porcentagem e matéria seca.

As características reológicas da farinha de trigo foram determinadas no alveógrafo Chopin, através da pesagem de 250 gramas de farinha e volume padrão de 129,4 mL de água, corrigido na base de $14 \%$ de umidade. Os parâmetros obtidos nos alveogramas foram tenacidade $(\mathrm{P})$, que mede a sobrepressão máxima exercida na expansão da massa $(\mathrm{mm})$; extensibilidade (L), que mede o comprimento da curva $(\mathrm{mm})$, relação tenacidade/extensibilidade $(\mathrm{P} / \mathrm{L})$ é a energia de deformação da massa $(\mathrm{W})$, que corresponde ao trabalho mecânico necessário para expandir a bolha até a ruptura, expressa em $10^{-4}$ Joules (J).

Do total de quatorze caracteres avaliados, dez foram empregados para análise de variância, e as médias comparadas através do desvio-padrão e, as médias do rendimento de grãos comparadas pelo teste de Tukey a $1 \%$ de probabilidade (STEEL e TorRIE, 1960), além disso, os dados foram empregados para estimativa dos coeficientes de correlação fenotípica. Para a realização das estimativas de distância genética foram empregadas todas as variáveis analisadas.

Foram geradas duas matrizes de dissimilaridade empregando distância Euclidiana média padronizada, devido à ausência de repetições para todas as variáveis analisadas. 
$\mathrm{Na}$ primeira, foram considerados todos os caracteres componentes da qualidade industrial e na segunda, foi incluído o caráter rendimento de grãos, utilizando o programa estatístico Genes (CRUZ, 2001). Os coeficientes de correlação fenotípica foram gerados através do programa estatístico SAS a partir do procedimento proc corr (SAS, 2002).

Com base nas matrizes de distâncias genéticas geradas, foram construídos dois dendrogramas, utilizando o método de agrupamento das médias das distâncias (UPGMA). Para a estimativa do ajuste entre a matriz de distância e o dendrograma gerado, foi calculado o coeficiente de correlação cofenético (r) (SoKal e RohlF, 1962).

Com o objetivo de melhorar a recomendação de cruzamentos a partir do estudo de distância genética, foi criado o ideotipo (genótipo ideal) a partir da média menos dois desvios- padrão $(\bar{x}-2 \sigma)$ para o caráter farinha de quebra e média mais dois desviospadrão $(\bar{x}+2 \sigma)$, para os demais caracteres. Desta forma, os genótipos foram classificados de acordo com a distância que representaram em relação ao ideotipo, sendo considerados os melhores genótipos aqueles que expressavam as menores distâncias em relação ao padrão (ideotipo).

\section{RESULTADOS E DISCUSSÃO}

De acordo com os resultados, foi possível detectar diferença entre os genótipos em pelo menos um desvio-padrão para os caracteres da qualidade industrial, indicando a existência de provável variabilidade fenotípica entre os 22 genótipos de trigo testados no trabalho (Tabela 1). Em relação ao rendimento de grãos, o genótipo ICA 5 expressou a maior produtividade com $3.407 \mathrm{~kg} \mathrm{ha}^{-1}$, contudo não diferenciou significativamente dos genótipos BRS 177 e Safira, os quais obtiveram médias de 3.093 e 2.993 $\mathrm{kg} \mathrm{ha}^{-1}$ respectivamente (Tabela 1 ).

Os genótipos BRS 208, Rubi, Ônix e Safira manifestaram os melhores desempenhos médios nas análises empregadas para avaliar a qualidade industrial. As cultivares Rubi e Safira foram os genótipos com maior destaque, evidenciando possível superioridade para seis caracteres (peso de hectolitro, força de glúten, extração de farinha, conteúdo de proteína, farinha de quebra, número de queda e índice de cor amarela " $+b^{\prime \prime}$ ) dos nove avaliados. Esses resultados revelam que estas constituições genéticas podem ser promissoras na obtenção de progênies transgressivas para a qualidade industrial do trigo.

Para a classificação das cultivares quanto à qualidade industrial do trigo, o Ministério da Agricultura Pecuária e do Abastecimento (MAPA) emprega o critério da alveografia (força de glúten representada pela letra W) (BRASIL, 1999). Para um genótipo ser classificado como trigo melhorador (qualidade industrial para fazer mesclas com trigos de $\mathrm{W}$ menor), é necessário que a força de glúten seja igual ou superior a $30010^{-4} \mathrm{~J}$. Desse modo, o desempenho observado para a força de glúten dos genótipos BR 18, CEP 24, PF 950354, Rubi, CD111 e Safira permitiram a classificação como trigos melhoradores. Considerando as cultivares CEP 24 e Rubi que, geralmente, expressam comportamento de trigo pão, com força de glúten entre $18010^{-4} \mathrm{~J}$ e 300 $10^{-4} \mathrm{~J}$, revela que ambiente testado contribui no bom desempenho dos genótipos para a qualidade industrial do trigo (Tabela 1). Por outro lado, os genótipos BRS 194 e ICA 5 com desempenho inferior à média menos um desvio-padrão, foram classificados como inferiores para força de glúten. Além destes, os genótipos BR 23, BRS 120, ICA 2 e ICA 7 compuseram o grupo de cultivares com qualidade industrial de trigo brando $\left(\mathrm{W}<18010^{-4} \mathrm{~J}\right)$.

A linhagem PF 950354 expressou ótimo desempenho para força de glúten, atingindo valor de $\mathrm{W}=51810^{-4} \mathrm{~J}$. Este desempenho possibilita sua utilização em misturas com cultivares de trigo de qualidade industrial para a fabricação de biscoitos (trigo brando), permitindo a obtenção de farinha tipo pão, atendendo a principal demanda do país (QuARIENTI, 1996). Apesar de demonstrar esta elevada qualidade, a linhagem PF 950354 não chegou a ser promovida como cultivar, possivelmente pelo seu reduzido potencial genético para o caráter rendimento de grãos (Tabela 1). Este fato expressa a necessidade da associação dos caracteres favoráveis para o rendimento de grãos e qualidade industrial em um genótipo.

Os valores do caráter número de queda (NQ), verificados para todos os genótipos à exceção de $B R$ 18 foram bastante elevados (NQ > 200 segundos), atendendo ao valor mínimo exigido pelos critérios do MAPA para classificação como farinhas de aptidão industrial (BRASIL, 1999). Por estes resultados, constata-se que as condições de ambiente no período da maturação fisiológica à colheita das plantas, podem ter favorecido a manutenção da qualidade do produto. Além disso, os resultados indicam a provável existência de variabilidade fenotípica para o caráter número de queda, o qual manifesta correlação negativa com a germinação na espiga (Lasztity, 2003). Assim, foi possível destacar os genótipos Rubi, CD111, Ônix e Safira, com desempenho superior para o caráter NQ, como possíveis fontes de genes de tolerância para o caráter germinação na espiga (Tabela 1). 


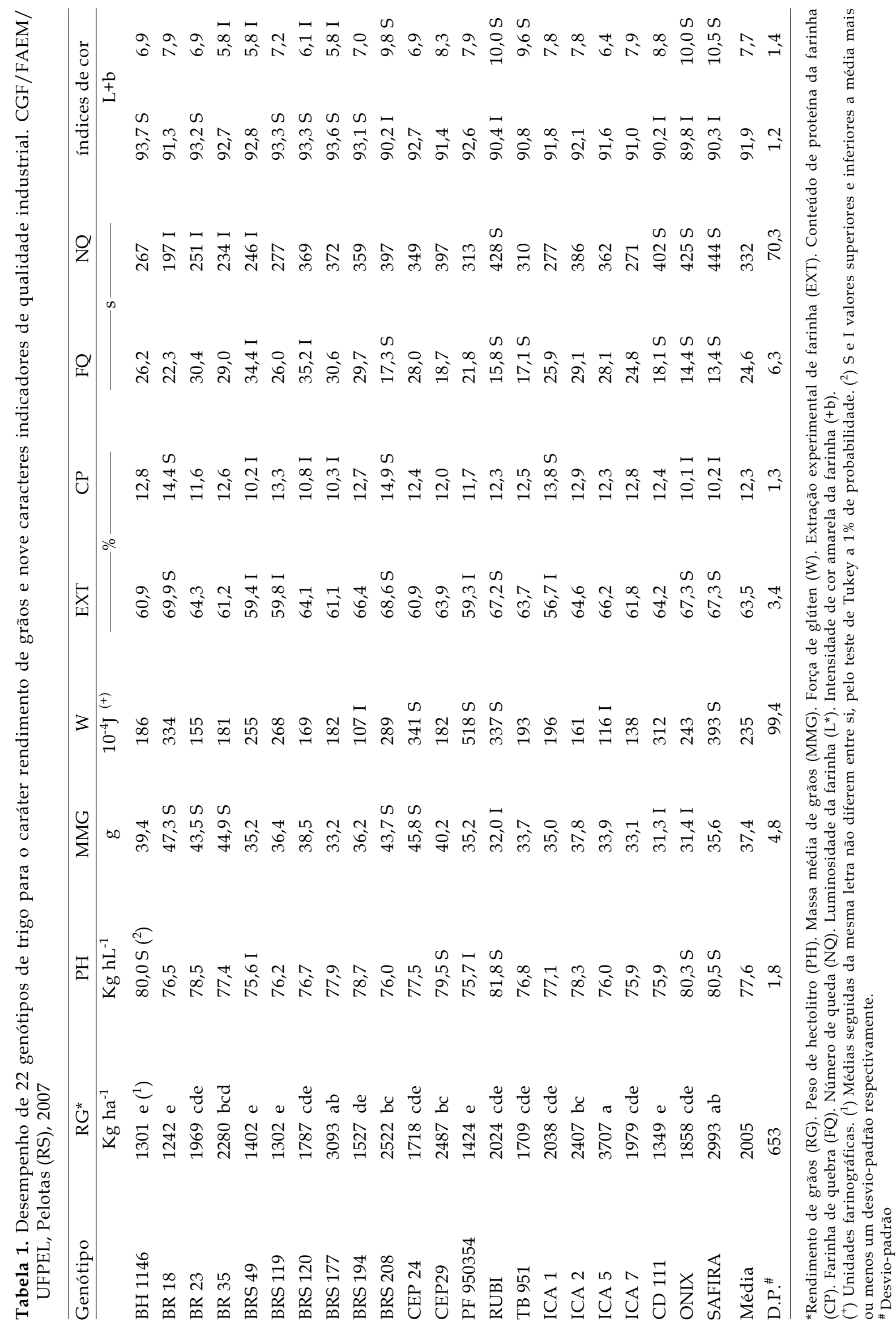


O conteúdo protéico do grão geralmente varia entre $9 \%$ e $15 \%$ do peso seco, sendo citado por alguns autores como o principal indicador da qualidade do produto final (PAYNE, 1987; ZANETTI et al., 2001; LASZTITY, 2003). Contudo, esta relação entre o conteúdo de proteína e a qualidade industrial não se confirmou para o grupo de genótipos testados neste trabalho. As cultivares BR18, BRS 208 e ICA 1 que apresentaram o maior conteúdo de proteína não expressaram superioridade para a força de glúten (Tabela 1).

É importante ressaltar o desempenho dos genótipos BRS 120, Ônix e Safira, com baixo conteúdo protéico e que evidenciaram comportamento distinto para a força geral de glúten. Desta forma, a cultivar BRS 120 foi classificada como trigo brando, Ônix como trigo pão e Safira como trigo melhorador. Portanto, a hipótese que o conteúdo protéico seja eficiente para predizer a qualidade industrial não teve respaldo nos resultados verificados com o conjunto de genótipos testados no ambiente de 2005 em Pelotas. Este comportamento concorda com os resultados constatados por TRETHOWAN et al. (2001), que ressaltam a importância da composição qualitativa da proteína, principalmente à combinação alélica das subunidades das gluteninas de alto e baixo peso molecular.

Considerando a avaliação dos parâmetros indicadores da qualidade industrial ser mais complexa, quando comparada com a avaliação fenotípica dos componentes do rendimento de grãos em trigo (LASZTITY, 2003), esta informação revela que os cruzamentos devem ser realizados para que a segregação das progênies seja a menor possível para o caráter de difícil mensuração. Desta forma, as cultivares BRS 208, Rubi e Safira, com excelente desempenho para qualidade industrial e bom desempenho agronômico, sejam os genitores com maior potencialidade para serem empregados na obtenção de progênies superiores. Apesar da superioridade para rendimento de grãos, os genótipos BRS 177 e ICA 5 tiveram reduzida qualidade industrial, possivelmente pela baixa freqüência de alelos favoráveis para este caráter. Segundo LORENCETTI et al. (2006) a frequência de genes de interesse complementar nos genitores é a chave para obtenção de progênies com superioridade genotípica. Desse modo, espera-se que a utilização de genitores-elite para a qualidade e com bom desempenho para rendimento de grãos (Safira, BRS 208 e Rubi) proporcione a obtenção de populações segregantes com elevada qualidade industrial, possibilitando ao melhorista focar sua atenção na segregação relacionada com os componentes do rendimento de grãos (LASZTiTY, 2003).

Os coeficientes de correlação fenotípica entre os componentes da qualidade industrial do trigo e rendimento de grãos revelaram que o caráter número de queda (NQ) evidenciou o maior número de associações significativas (Tabela 2), contudo, todas de magnitude média. Por outro lado, a farinha de quebra (FQ) evidenciou correlações com os caracteres extração de farinha, número de queda e força de glúten, considerados de grande importância para o melhoramento genético da qualidade industrial de trigo (Kuchel et al., 2006). Segundo Giroux et al. (2000), o caráter FQ é controlado por um gene maior ou poucos genes de expressão similar, indicando a possibilidade de sucesso na transferência do caráter em cruzamento artificiais.

Os coeficientes de correlação entre o caráter FQ e os indicadores da cor de farinha branca $(r=-0,84)$ e cor de farinha amarela $(0,94)$ evidenciaram as maiores magnitudes entre todos os caracteres avaliados (Tabela 2). Segundo GuтKоSKI et al. (2003), quanto maior for à farinha de quebra, menor será a dureza do grão de trigo. Esse fato ocorre devido à ausência de pontes de ligações de enxofre (S-S) entre as proteínas, ocasionando descontinuidade da matriz protéica. Desta forma, genótipos de trigo em cujos grãos havia ausência de dureza evidenciam fraca aderência entre os grânulos de amido e proteína, expressando a obtenção de farinha com maior intensidade de cor branca pela exposição dos grânulos de amido. Por outro lado, quando a constituição genética promove elevada dureza dos grãos (matriz protéica contínua) é verificada grande dificuldade para separação do endosperma (semolina) dos demais componentes do grão no processo de moagem. Isto possibilita a obtenção de farinhas com menor intensidade de cor branca $\left(\mathrm{L}^{*}\right)$ e maior do componente de cor amarela $\left(+b^{*}\right)$ (GIROux et al., 2000).

$\mathrm{O}$ caráter peso de hectolitro $(\mathrm{PH})$ somente evidenciou correlação significativa com o número de queda (NQ). Esta associação pode justificar o emprego da técnica de $\mathrm{PH}$ para classificar o trigo no momento da comercialização pelo produtor (QUARIENTI, 1996). A massa de mil grãos (MMG) revelou correlação significativa com os caracteres número de queda e proteína da farinha. Estes resultados revelam para o grupo de genótipos testados que os caracteres $\mathrm{PH}$ e MMG não contribuem expressivamente para a compreensão dos fatores que afetam a qualidade industrial do trigo.

O conjunto de proteínas de reserva do trigo (glúten) tem sido considerado o principal componente da qualidade, evidenciando forte associação com a qualidade do produto final (ZANETTI et al., 2001). A ausência de correlação $(r=-0,04)$ entre o conteúdo de proteína e a força geral de glúten, segundo PAYNE (1987), revelam maior importância da fração qualitativa em relação a fração quantitativa da proteína. 
Tabela 2. Coeficientes de correlação de Spearman entre dez caracteres considerando 22 genótipos de trigo. CGF/ FAEM/UFPEL, Pelotas (RS), 2007

\begin{tabular}{lcccccccccc}
\hline & $\mathrm{RG}^{+}$ & $\mathrm{PH}$ & $\mathrm{MMG}$ & $\mathrm{W}$ & $\mathrm{EXT}$ & $\mathrm{CP}$ & $\mathrm{FQ}$ & $\mathrm{NQ}$ & $\mathrm{L}$ & $+\mathrm{b}$ \\
\hline RG & 1 & $-0,26$ & 0,23 & $-0,26$ & $0,51^{*}$ & $-0,76^{*}$ & 0,07 & $0,54^{*}$ & $-0,19$ & 0,27 \\
PH & - & 1 & $-0,10$ & $-0,02$ & 0,32 & $-0,30$ & 0,37 & $0,46^{*}$ & $-0,16$ & 0,39 \\
MMG & - & - & 1 & 0,04 & 0,13 & $0,43^{*}$ & 0,24 & $-0,43^{*}$ & 0,29 & $-0,27$ \\
W & - & - & - & 1 & 0,03 & $-0,05$ & $0,48^{*}$ & 0,14 & $-0,27$ & $0,42^{*}$ \\
EXT & - & - & - & - & 1 & 0,10 & $0,45^{*}$ & $0,43^{*}$ & $-0,56^{*}$ & $0,51^{*}$ \\
CP & - & - & - & - & - & 1 & 0,11 & $-0,32$ & $-0,12$ & 0,11 \\
FQ & - & - & - & - & - & - & 1 & $0,48^{*}$ & $-0,84^{*}$ & $0,94^{*}$ \\
NQ & - & - & - & - & - & - & - & 1 & $-0,48^{*}$ & $0,54^{*}$ \\
L & - & - & - & - & - & - & - & - & 1 & $-0,86^{*}$ \\
$+\mathrm{b}$ & - & - & - & - & - & - & - & - & - & 1 \\
\hline
\end{tabular}

${ }^{+}$Rendimento de grãos (RG). Peso de hectolitro (PH). Massa média de grãos (MMG). Força de glúten (W). Extração experimental de farinha $(\mathrm{EXT})$. Conteúdo de proteína da farinha (CP). Farinha de quebra (FQ). Número de queda (NQ). Luminosidade (L). Intensidade de cor amarela $(+b)$.

$*$ significativo a $5 \%$ probabilidade pelo teste $\mathrm{F}$.

A relação inversa estabelecida entre o conteúdo de proteína e o rendimento de grãos em trigo (Rousset et al., 1992; Mariam e LaRTER, 1996; TREtHOWAN et al., 2001) foi confirmada no presente trabalho $(\mathrm{r}=$ $0,76)$, conforme evidenciado na tabela 2. Esse comportamento pode ser explicado com base na assimilação do nitrogênio, que está entre os processos fisiológicos de maior gasto energético nas plantas. Em gramíneas, a absorção e assimilação de nitrato $\left(\mathrm{NO}^{3-}\right.$ ) e amônio $\left(\mathrm{NH}^{4+}\right)$ são responsáveis pelo consumo de $15 \%$ a $23 \%$ do total de carboidratos fixados pela planta (Bloom et al., 1992). Desta forma, quanto maior for a eficiência de uma constituição genética em absorver nitrogênio e convertê-lo em proteína, maior será o consumo de carboidratos, fato que determina a redução do acúmulo de amido e, conseqüentemente, decréscimo no rendimento de grãos.

O emprego das técnicas de dispersão gráfica (dendrogramas) para representar a estimativa de distância genética viabiliza a avaliação de grande conjunto de dados e, permite a formação de grupos de genótipos com maior similaridade genética entre si (BARBosa-Neto et al., 1996). Essas ferramentas auxiliam os pesquisadores na indicação de genitores mais contrastantes e pode possibilitar a obtenção de indivíduos geneticamente superiores com base na ação de genes complementares (BERTAN, 2005; FUFA et al., 2005). As estimativas de distâncias genéticas entre 22 genótipos de trigo testados estão apresentadas nas figuras 1 e 2, representando os caracteres de qualidade sem e com a participação do caráter rendimento de grãos respectivamente.
Apesar das vantagens da utilização de figuras que representam as estimativas de distância genética em dendrogramas, é necessário ressaltar a importância da verificação das médias dos genótipos para os caracteres avaliados; o desempenho manifestado é forte indicador da freqüência e da expressão dos alelos de interesse (Oliveira et al., 1996). Assim, para indicação de genitores, com base em distância genética, é importante incluir a observação das médias para os caracteres de interesse (FufA et al., 2005).

Considerando os componentes da qualidade industrial, a estimativa da distância genética permitiu a formação de quatro grupos distintos, estabelecidos pelo critério do truncamento da distância média conforme evidenciado na Figura 1. Com base na distância genética em relação ao ideotipo (constituição genética considerada ideal para o conjunto de genótipos estudados), os genótipos que compõem o grupo III (BRS 208, CD 111, Ônix, Rubi, CEP 24 e Safira), possivelmente, expressaram a maior freqüência de genes favoráveis para a qualidade industrial.

Nos genótipos BR 18 e PF 950354, respectivamente, dos grupos II e IV constatou-se desempenho intermediário para qualidade industrial (Figura 1). No grupo I, pode ser observada a inclusão do maior número de genótipos (quatorze), possivelmente pela menor freqüência de alelos favoráveis para a qualidade industrial considerando todos os genótipos testados. 


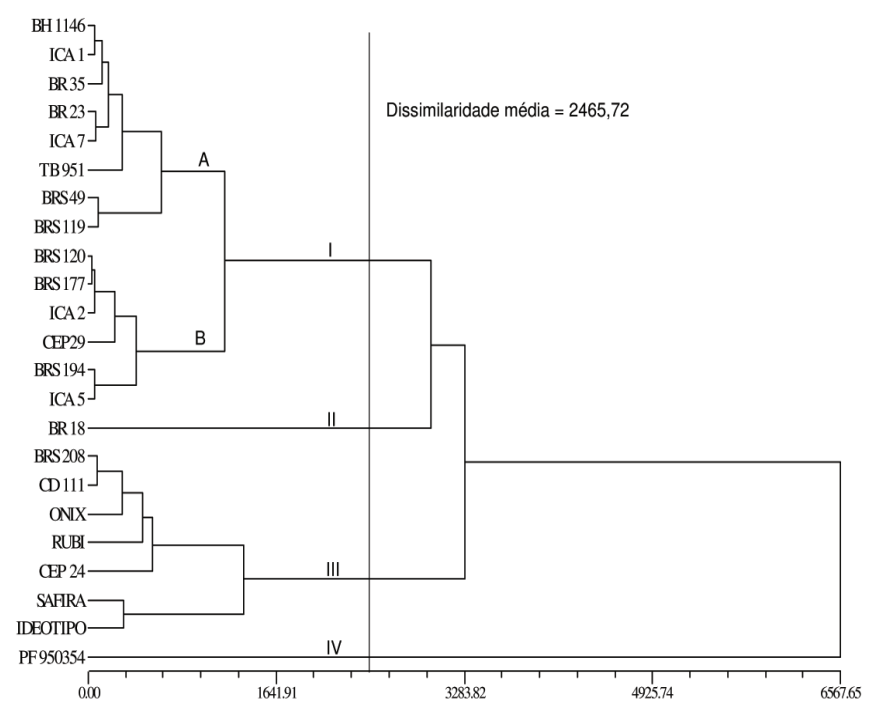

Figura 1. Dendrograma de dissimilaridade genética resultante da análise de agrupamento de treze caracteres da qualidade industrial em 22 genótipos de trigo mais o ideotipo, obtido pelo método de agrupamento UPGMA. O valor de correlação cofenético é de 0,80. CGF/FAEM/UFPEL, Pelotas (RS), 2007.

A inclusão do caráter rendimento de grãos para a estimativa da distância genética revelou a formação de dois grandes grupos, empregando o critério de truncamento da dissimilaridade média (Figura 2). Em relação às inferências realizadas a partir da análise visual das Figuras 1 e 2, os coeficientes de correlação cofenético foram de elevada magnitude $(r=0,80$, e $r=0,76$, para as Figuras 1 e 2 respectivamente), indicando ser o ajuste entre a matriz original de dissimilaridade e a representação gráfica das distâncias de elevada fidedignidade (VIEIRA, et al., 2005).

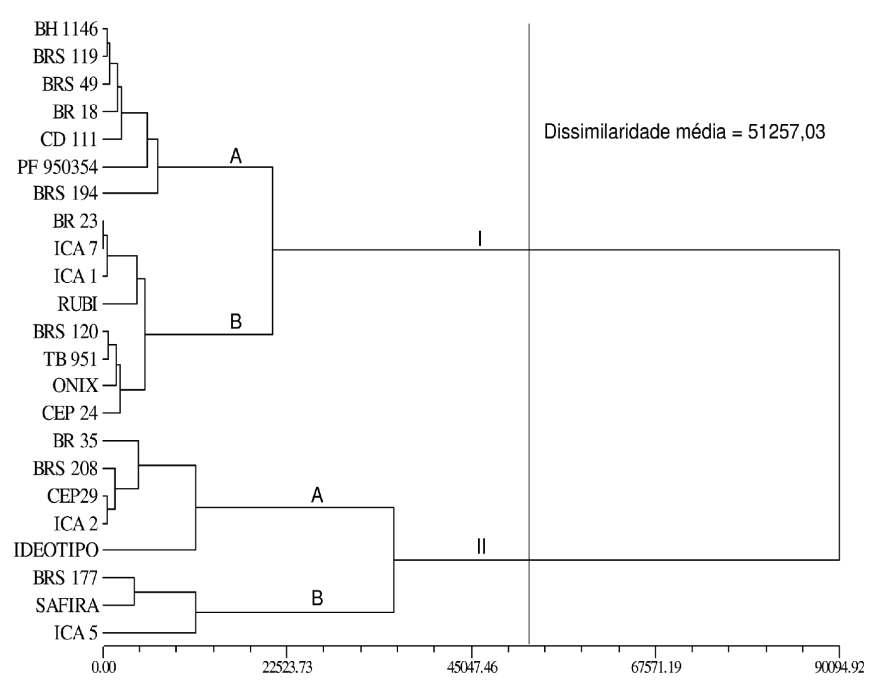

Figura 2. Dendrograma de dissimilaridade genética resultante da análise de agrupamento de quatorze caracteres mais o rendimento de grãos em 22 genótipos de trigo mais o ideotipo, obtido pelo método de agrupamento UPGMA. O valor de correlação cofenético é de 0,76. CGF/FAEM/UFPEL, Pelotas (RS), 2007.
Com base na provável distância genética (Figura 1 e Figura 2), um possível cruzamento seria entre genótipos BRS 177 (constituição genética elite para o rendimento de grãos e de baixa qualidade) e PF 950354 (genótipo de excelente qualidade industrial e reduzido potencial de rendimento de grãos) os quais agruparam em grupos distintos. É provável que a população segregante deste cruzamento expresse elevada freqüência de heterozigose nos locos envolvidos com o rendimento e qualidade de grãos; em conseqüência, haverá expressiva segregação em muitos locos. Este fato dificulta o trabalho do pesquisador na seleção de plantas superiores para todos os caracteres de interesse, pois necessita-se um número muito grande de indivíduos na população, para representar a toda a variabilidade genética envolvida e possibilitar a obtenção de um indivíduo recombinante superior (AlLARD, 1999; CARVALHO et al., 2001). Para incrementar a eficiência de um programa de melhoramento genético vegetal, é importante reunir o máximo de informações sobre o germoplasma disponível para a escolha mais adequada de genitores. Além disso, aliar este conhecimento com a capacidade combinatória que estes genótipos manifestam (BERTAN, 2005).

Na tabela 3, estão discriminadas as distâncias em que os genótipos testados ficam em relação ao ideotipo, de modo que as primeiras constituições genéticas expressam a maior freqüência de alelos de interesse. Em relação aos caracteres da qualidade industrial, a cultivar Safira evidenciou maior similaridade com o ideotipo, seguida dos genótipos, PF 950354, Rubi, CEP 24 e CD 111. Estes genótipos evidenciam elevada freqüência de genes favoráveis para a qualidade de panificação, entretanto o desempenho é bastante variável para o rendimento de grãos (Tabela 1).

Considerando todos os caracteres analisados, observou-se nas cultivares BRS 208, Safira, CEP 29, ICA 2 e BR 35 respectivamente, a maior similaridade genética com o ideotipo (Tabela 3). Nas cultivares BRS 208, Safira e Rubi a média geral foi superior para rendimento de grãos e comportamento superior a intermediário em relação aos caracteres da qualidade, o que pode ser confirmado em relação à distância ao ideotipo (Tabela 3). Esses genitores quando utilizados em blocos de cruzamentos podem proporcionar a obtenção de populações segregantes de elevada qualidade industrial e que manifestem baixa segregação para os locos responsáveis pela expressão deste caráter, proporcionando ao melhorista focar sua atenção naquela segregação relacionada com os componentes do rendimento de grãos, aumentando a eficiência do programa de melhoramento. 
Tabela 3. Estimativa da distância de similaridade genética de 22 genótipos em relação ao ideotipo formado considerando caracteres da qualidade industrial e rendimento de grãos. CGF/FAEM/UFPEL, Pelotas (RS), 2007

\begin{tabular}{|c|c|c|c|c|c|}
\hline \multirow{2}{*}{ Genótipos } & \multicolumn{2}{|c|}{ Com rendimento de grãos } & \multirow{2}{*}{ Genótipos } & \multicolumn{2}{|c|}{ Sem rendimento de grãos } \\
\hline & Distância do ideotipo & Classificação* & & Distância do ideotipo & Classificação \\
\hline BRS 208 & 4670,5 & $1^{\mathrm{o}}$ & SAFIRA & 1100,4 & $1^{\mathrm{o}}$ \\
\hline SAFIRA & 8045,3 & $2^{\circ}$ & PF 950354 & 1174,9 & $2^{\circ}$ \\
\hline CEP29 & 9382,8 & $3^{\circ}$ & RUBI & 2503 & $3^{\circ}$ \\
\hline ICA 2 & 12439,6 & $4^{\mathrm{o}}$ & CEP 24 & 2825,1 & $4^{\mathrm{o}}$ \\
\hline BR 35 & 19077,8 & $5^{\circ}$ & CD 111 & 3107,3 & $5^{\mathrm{o}}$ \\
\hline BRS 177 & 19545,3 & $6^{\circ}$ & BRS 208 & 3749,4 & $6^{\circ}$ \\
\hline RUBI & 27468,3 & $7^{\circ}$ & ONIX & 5243,9 & $7^{\circ}$ \\
\hline ICA 1 & 32549,6 & $8^{\circ}$ & BRS 119 & 6223,4 & $8^{\circ}$ \\
\hline ICA 7 & 40137,7 & $9^{\circ}$ & BR 18 & 6441,7 & $9^{\circ}$ \\
\hline BR 23 & 40562,6 & $10^{\circ}$ & BRS 49 & 7444,6 & $10^{\circ}$ \\
\hline ONIX & 44915,6 & $11^{\circ}$ & CEP29 & 8059,3 & $11^{\circ}$ \\
\hline ICA 5 & 46051,4 & $12^{\circ}$ & BRS 177 & 8234,1 & $12^{\circ}$ \\
\hline BRS 120 & 55774,9 & $13^{\circ}$ & ТВ 951 & 8494,7 & $13^{\circ}$ \\
\hline CEP 24 & 57873,2 & $14^{\mathrm{o}}$ & BRS 120 & 8917,8 & $14^{\mathrm{o}}$ \\
\hline ТВ 951 & 64250,5 & $15^{\circ}$ & ICA 2 & 9069,4 & $15^{\circ}$ \\
\hline BRS 194 & 91528,4 & $16^{\circ}$ & ICA 1 & 9093,7 & $16^{\circ}$ \\
\hline PF 950354 & 96272,8 & $17^{\circ}$ & BH 1146 & 9683,4 & $17^{\circ}$ \\
\hline BRS 49 & 105574,4 & $18^{\circ}$ & BR 35 & 10824,4 & $18^{\circ}$ \\
\hline CD 111 & 110004,7 & $19^{\circ}$ & BR 23 & 11619 & $19^{\circ}$ \\
\hline BRS 119 & 120754,6 & $20^{\circ}$ & ICA 5 & 11722,3 & $20^{\circ}$ \\
\hline BН 1146 & 124168,3 & $21^{\circ}$ & ICA 7 & 12078,5 & $21^{\circ}$ \\
\hline BR 18 & 131354,8 & $22^{\circ}$ & BRS 194 & 12353,5 & $22^{\circ}$ \\
\hline
\end{tabular}

* Classificação de genótipos com base nas estimativas de distância em magnitude crescente em relação ao ideotipo.

\section{CONCLUSÕES}

1. Existe variabilidade genética entre os genótipos de trigos testados para caracteres indicativos da qualidade industrial de grãos, e esta pode ser explorada na recomendação das cultivares aos produtores e para compor blocos de cruzamentos em programas de melhoramento genético.

2. Os genótipos BRS 208, Rubi e Safira podem ser explorados para a formação de populações segregantes com elevado potencial de rendimento e qualidade de grãos por meio de cruzamentos artificiais.

3. O conteúdo de proteína não foi eficiente para predizer a qualidade industrial, além de evidenciar associação negativa com o rendimento de grãos.

\section{REFERÊNCIAS}

ALLARD, R.W. Principles of plant breeding. New York, J. Wiley, 1999. p. 485.

BARBOSA-NETO, J.F.; SORRELLS, M.E.; CISAR, G. Prediction of heterosis in wheat using coefficient of parentage and RFLPbased estimates of genetic relationship. Genome, Montreal, v.39, n.6, p.1142-1149, 1996.

BERTAN, I. Distância genética como critério para escolha de genitores em programas de melhoramento de trigo (Triticum aestivum L). 2005. 100f. Dissertação (Mestrado em Agronomia) Curso de Pós-Graduação em Agronomia, FAEM-UFPel, Pelotas.

BLOOM, A.J.; SUKRAPANNA, S.S.; WARNER, R.L. Root respiration associated with ammonium and nitrate absorption and assimilation by barley. Plant Physiology, Berlin, v. 99, n.4, p.1294-1301, 1992. 
BRASIL. Ministério da agricultura. Instrução normativa n.1 de 27 de janeiro de 1999. Diário oficial (República Federativa do Brasil), p.132, Brasília, 29 de janeiro de 1999.

CARVALHO, F.I.F; SILVA, S.A.; KUREK, A.J.; MARCHIORO, V.S. Estimativas e implicações da herdabilidade como estratégia de seleção. Pelotas: Editora e gráfica da UFPel, 2001. 99p.

COMISSÃO SUL BRASILEIRA DE PESQUISA DE TRIGO. Recomendações da Comissão Sul-Brasileira de Pesquisa de Trigo. Editora: EMBRAPA-CNPT, Passo Fundo, 2005. 74p.

CRUZ, C.D. Programa Genes: Aplicativo computacional em genética e estatística, Viçosa: UFV, 2001. 648p.

FUFA, H.; BAENZIGER, P.S.; BEECHER, B.S.; DWEIKAT, I.; GRAYBOSCH, R.A.; ESKRIDGE, K.M. Comparison of phenotypic and molecular marker-based classifications of hard red winter wheat cultivars. Euphytica, Dordrecht, v.145, n.2, p.133-146, 2005.

GIROUX, M.J.; TALBERT, L.; HABERNICHT, D.K.; LANNING, S.; HEMPHILL, A.; MARTIN, J. M. Associations of puroindoline sequence type and grain hardness in hard red spring wheat. Crop Science, Madison, v.40, n.2, p.370-374, 2000.

GUTKOSKI, L.C.; NODARI, M.L.; NETO, R.J. Avaliação de farinhas de trigos cultivados no Rio Grande do Sul na produção de biscoitos. Ciência e Tecnologia de Alimentos, Campinas. v.23 (supl.), p. 91-97. 2003.

HUIFEN, H.E.; HOSENEY, R.C. Gluten, a theory of hewitt controls bread-making quality. Gluten proteins. Saint Paul: American Association of Cereal Chemistry, 1991. 794p.

KUCHEL, H.; LANGRIDGE, P.; MOSIONEK, L.; WILLIAMS, K.; JEFFERIES, S.P. The genetic control of milling yield, dough rheology and baking quality of wheat. Theoretical and Applied Genetics, Berlin, v.112, n.8, p.1487-1495. 2006.

LASZTITY, R. Prediction of wheat quality - Success and doubts. Periodica Polytechnica Chemistry Engineering, Budapest, v.46, n.1, p. 39-49, 2003.

LORENCETTI, C.; CARVALHO, F.I.F.; OLIVEIRA, A.C.; VALÉRIO, I.P.; HARTWIG, I.; MARCHIORO, V.S.; VIEIRA, E.A. Retrocruzamento como uma estratégia de identificar genótipos e desenvolver populações segregantes promissoras em aveia. Ciência Rural, Santa Maria, v.36, n.4, p.1118-1125, 2006.

MANDARINO, J.M.G. Aspectos Importantes para a qualidade do Trigo. Londrina: Embrapa - CNPSo, 32p. (Embrapa CNPSo. Documentos, 60, 1993)

MARIAM, G.H.; LARTER, E.N. Genetic response to index selection for grain yield, kernel weight and per cent protein in four wheat crosses. Plant Breeding, Berlin, n.6, v.115, p.459$464,1996$.

MITTELMANN, A.; NETO, J.F.B.; CARVALHO, F.I.F.; LEMOS, M.C.I.; CONCEIÇÃO, L.D.H. Herança de caracteres do trigo relacionados à qualidade de panificação. Pesquisa Agropecuária Brasileira, Brasília, v.35, n.5, p.975-983, 2000.
MORENO, A.J. Clima do Rio Grande do Sul. Porto Alegre: Secretaria da Agricultura/RS, 1961. 41p.

OLIVEIRA, A.C. de; RICHTER, T.; BENNETZEN, J.L. Regional and racial specificities in sorghum germoplasm assessed with DNA markers. Genome, Montreal v.39, p.579-587. 1996.

PAYNE, P.I. Genetics of wheat storage proteins and the effect of allelic variation on bread-making quality. Annual Review. Plant Physiology and Plant Molecular Biology, Berlin, v.38, p.141-153, 1987.

QUARIENTI, E. M. Qualidade industrial do trigo. 2 ed. Passo Fundo: EMBRAPA- CNPT, 1996. 36p. (EMBRAPA-CNPT. Documentos, n. 27)

ROUSSET, M.; CARRILLO, J. M.; QUALSET, C.O.; KASARDA, D.D. Use of recombinant inbred lines of wheat for study of associations of high-molecular-weight glutenin subunit alleles to quantitative traits. Theoretical Applied Genetics, Berlin, v.83, n.4, p.403-412, 1992.

SAS Learning Edition. Getting Started with the SAS Learning Edition, Care, North Carolina: SAS Institute, 2002.81p.

STEEL, R.G.D.; TORRIE, J.H. Principles and procedures of statistics; with special reference to the biological sciences. New York : McGraw-Hill, 1960. 481p.

SOKAL, R.R.; ROHLF, F.J. The comparison of dendrograms by objective methods. Taxon, Berlin, v.11, n.1, p.30-40, 1962.

TRETHOWAN, R.M.; PEÑA, R.J.; VAN GINKEL, M. The effect of indirect test grain quality on the grain yield and industrial quality of bread wheat. Plant Breeding, Berlin, v.120, n.6, p.509$512,2001$.

VIEIRA, E.A.; CARVALHO, F.I.F.; OLIVEIRA, A.C.; BENIN, G.; ZIMMER, P.D.; SILVA, J.A.G.; MARTINS, A.F.; BERTAN, I.; SILVA, G.O.; SCHMIDT, D.A.M. Comparação entre medidas de distância genealógica, morfológica e molecular em aveia em experimentos com e sem a aplicação de fungicida. Bragantia, Campinas, v.64, n.1, p.51-60, 2005.

ZANETTI, S.; WINZELER, M.; FEUILLET, C.; KELLER, B.; MESSMER, M. Genetic analysis of bread-making quality in wheat and spelt. Plant Breeding, Berlin, v.120, n.1, p.13-19, 2001. 